\title{
Analysis on Total Factor Productivity of Chinese Information Service Industry and Influencing Factors
}

\author{
Fang Xia ${ }^{1}$ \\ Changchun University of Chinese Medicine \\ Changchun, 130117,China \\ Email :xiafang4250126.com \\ Bingbing Zhao ${ }^{2}$ \\ Air Force Aviation University of China \\ Changchun, 130022,China \\ Email: zhaobingbing@126.com

\section{Zixu Hao ${ }^{3}$} \\ Changchun University of Chinese Medicine \\ Changchun, 130117, China \\ Email : hzx20160611@163.com
}

\begin{abstract}
The paper uses the productivity index based on data envelopment analysis (DEA) to calculate the total factor productivity (TFP) from 2008 to 2014, and also compares the differnces of TFP changes in three regions: eastern, central and western part. . Then we use the panel data model to seek and discuss the factors affecting the regional difference of total factor productivity growth. Results indicate that Chinese information service industry's total factor productivity shows a rising trend; the investment on education level and information level has a significant role in promoting the improvement of technological progress, technology efficiency and productivity; in addition, $\mathrm{R} \& \mathrm{D}$, government behavior and urbanization are the important factors that affect regional difference of the development of Chinese information service industry.
\end{abstract}

CENet 2017

22-23 July 2017

Shanghai, China

\footnotetext{
${ }^{1}$ Speaker

${ }^{2}$ This study is supported by Scientific research plan projects of Jilin Education

Department (JJKH20170744SK) and Changchun Chinese Medicine Bureau of Science Department (2016200)

${ }^{3}$ Correspongding Author
} 


\section{Introduction}

With the increasing maturity of the Internet industry, information service industry becomes the new growth point and strong engine of China's economic development, and boosts production and consumption. So it is particularly important to study the endogenous growth of its economy. In New-Classical Theory of Economic Growth, the total factor productivity(TFP) is the core to measure the economic endogenous growth; its changes can reflect the industry development level and trend clearly.

Abramovitz studied the America economy in 1869 1878, founded that there were other contributing factors of output growth besides the inputs growth of total factor productivity [1]. American scientists Cobb C.W.C and P.H.D Douglas(1928) put forward the famous CobbDouglas production function[2]. Recently, R.Solow asserted that total factor productivity growth was the main source of American economic growth in a constant scale reward, and hicks neutral and profit maximization conditions[3]. In 1984, R.D Banker, A. Charnes and WW.Cooper created $\mathrm{BC}^{2}$ model. $\mathrm{C}^{2} \mathrm{R}$ and $\mathrm{B}^{2} \mathrm{C}$ model were used to study the productivity technical effectiveness[4]. Fare(1985)[5] developed the measurement method of total factor productivity change, and also successfully took the experience analysis. In 1994, Fare etc. came up with non-parametric Malmquist index of the total factor productivity growth rate based on DEA[6]. In recent years the relative researches about TFP haveappeared in China. Ping $\mathrm{Hua}(2005)[7]$ measured the total factor productivity of the variance in 29 Chinese provinces bewteen 1993 and2001, and the result demonstrates that a high level of education has a positive effect on improving efficiency, technical progress and productivity growth. Xiguo Yin(2008) [8] used the nonparametric productivity index basedon provincial panel data to measure the total factor productivity of China. The research showed that international trade and direct foreign investment combining with human capital has an outstanding promotion to the China productivity growth, especially on promoting technology progress as well as the technical efficiency improvement.

In this paper, the data development analysis method is used to measure the TFP of China's information service industry and the situation of the eastern, central and western regions are discussed respectively. Then, we analyzed the main factors influencing the information service industry in China by panel data regress. Finally, according to different factors, the impact of industry is to determine the direction of industrial development.

\section{Methods and the Data}

\subsection{Calculation of Explanatory Variables}

The article introduces the Malmquist productivity index by the distance function $C^{2} R$ of DEA model.According to Shephard (1970), the output function which represents production set $\mathrm{S}^{\mathrm{t}}$ from $(\mathrm{t})$ to $(\mathrm{t}+1)$ period is defined as follow:

$$
S^{t}=\{(x, y) \mid \text { in t period }\}
$$

For input $x \in R_{+}^{N}$, output $y \in R_{+}^{N}$ the t production possibility set $\mathrm{S}^{\mathrm{t}}$ is defined as:

$$
D_{0}^{t}\left(x^{t}, y^{t}\right)=\inf \left\{\theta \mid\left(x^{t}, y^{t} / \theta\right) \in S^{t+1}\right\}=\left(\sup \left\{z \mid\left(x^{t}, z y^{t}\right) \in S^{t}\right\}\right)^{-1}
$$

Based on the existing research, by weighing the pros and cons of TFP productivity 
measurement, this paper tries to use the non-parameter productivity index method in the production function to measure and analysze the total factor productivity growth of China's information service from 2008 to 2014, and compare the difference of regional development.

In this article, we mainly studied from the perspective of investment research on the total factor productivity changes in Chinese information service industry, he reference technology is defined as follows:

$$
\begin{gathered}
L^{\prime}\left(y^{t} \mid C, S\right)=\left\{\left(x_{1}^{t}, \ldots, x_{N}^{t}\right): y_{k, m}^{t} \leq \sum_{k=1}^{K} z_{k}^{t} y_{k, m}^{t}, m=1, \ldots, M ;\right. \\
\left.\sum_{\mathrm{k}=1}^{K} z_{k}^{t} x_{k, n}^{t} \leq x_{k, n}^{t}, n=1, \ldots, N ; z_{k}^{t} \geq 0, k=1, \ldots, K\right\}
\end{gathered}
$$

Among them, $z$ means the weight of each cross section observation values. According to the research of Fare, etc. (1994), two geometric average of productivity index can be used to calculate productivity change, and its equivalent form is as follows:

$$
M_{0}\left(x^{t}, y^{t}, x^{t+1}, y^{t+1}\right)=\frac{d_{0}^{t}\left(x^{t+1}, y^{t+1}\right)}{d_{0}^{t}\left(x^{t}, y^{t}\right)} \times \sqrt{\frac{d_{0}^{t}\left(x^{t+1}, y^{t+1}\right)}{d_{0}^{t+1}\left(x^{t+1}, y^{t+1}\right)} \times \frac{d_{0}^{t}\left(x^{t}, y^{t}\right)}{d_{0}^{t+1}\left(x^{t}, y^{t}\right)}}
$$

Because changes of productivity index can be decomposed into technical efficiency change (EC) and the technological progress (TP), and also the technical efficiency change index can be further decomposed into pure technical efficiency (PC) and scale efficiency index (SC), therefore, estimation $(5)$ can also be expressed as follows: $M_{i}\left(\mathrm{x}^{t+1}, y^{t+1}, x^{t}, y^{\prime}\right)=\left\{\left[\frac{D_{i}^{t}\left(x^{t}, y^{t}\right)}{D_{i}^{i}\left(x^{t+1}, y^{t+1}\right)}\right]\left[\frac{D_{i+1}^{t+1}\left(x^{t}, y^{t}\right)}{D_{i}^{t+1}\left(x^{t+1}, y^{t+1}\right)}\right]\right\}^{1 / 2}=\frac{D_{i}^{t}\left(x^{t}, y^{t}\right)}{D_{i}^{t+1}\left(x^{t+1}, y^{t+1}\right)}\left[\frac{D_{i}^{t+1}\left(x^{t+1}, y^{t+1}\right)}{D_{i}^{t}\left(x^{t+1}, y^{t+1}\right)} \times \frac{D_{i+1}^{t+1}\left(x^{t}, y^{t}\right)}{D_{i}^{t}\left(x^{t}, y^{t}\right)}\right]^{1 / 2}=E C \times T P=P C \times S C \times T P$

\subsection{Model Setting and Explained Variable}

American economist Denison has carried on the classification and quantitative analysis on the influencing factors of total factor productivity growth, which were subdivided into scale economy, the improvement of resource allocation and knowledge progress three factors. Ultimately, his research provided a good analytical framework for the study of total factor productivity. Compared with the analysis of other researchers, this article will divide the main factors of TFP growth affecting China's regional information service industry into the informatization level, education level, $R \& D$ investment, the government behavior and the level of urbanization, etc., and put forward the following hypothesis.

\subsubsection{Model Setting}

In the process, we analyze the differences between the contributingfactors by using static panel data model. According to the time and cross section features of panel data, the model form must be tested to get effective parameter estimation before estimating. So we use the Hausman test to ensure the validity of the estimation. By the Hausman test, we use fixed intercept model and optimize model by adding index gradually, after that, the growth of total factor productivity under the scope of the research is regarded as explained variable, and the model is set as follows:

$$
\ln T F P_{\text {it }}=\beta_{0}+\beta_{1} \times \ln I D I_{\mathrm{i}, \mathrm{t}-1}+\beta_{2} \times \ln E D U_{i, t-1}+\beta_{3} \times \ln R D_{i, t-1}+\beta_{4} \times \ln G O V_{\mathrm{i}, \mathrm{t}-1}+\beta_{5} \times \ln U R B_{i, t-1}
$$

$\mathrm{TFP}_{\text {it }}$, as the dependent variable, is the growth rate of total factor productivity in 
information services. As the independent variables, information development (IDI), education development level (EDU), research and development investment (R\&D), the government behavior (Govern), and urbanization (Urban) all respectively affect the interpretation of the TFP change.

\subsubsection{Explained Variables Description}

(1) Information Development (IDI)

$$
I D I_{i, t-1}=\inf _{i, t-1} / g d p_{i, t-1}
$$

inf $_{i, t-1}$ means i region's Information Service Industry output value in t-1 year; $g d p_{i, t-1}$ means i Region's GDP output value in t-1 year.Education Development Level (EDU) $E D U_{i, t-1}=\sum_{i=1}^{n} p_{i, t-1} y_{i, t-1}$

$p_{i, t-l}$ refers to a certain level of education corresponding to the proportion of the population, $y_{i, t-1}$ refers to the education level corresponding to the number of years of education. The specific practices can refer to Qingwang Guo(2005)[9] .

(2) Research and Development Investment (RD)

$$
R D_{i, t-1}=r d_{i, t-1} / g d p_{i, t-1}
$$

$r d_{i, t-1}$ means i Region's research and development investment in t-1 year; $g d p_{i, t-1}$ means the same as above.

(3) government behavior (GOV)

$$
\text { GOV }_{i, t-1}=\text { govern }_{i, t-1} / \text { gdp }_{i, t-1}
$$

govern $_{i, t-1}$ means i Region's government investment in $\mathrm{t}-1$ year; $g d p_{i, t-1}$ means the same as above.

(4) Urbanization (URB)

$$
U R B_{i, t-1}=\text { urban }_{i, t-1} / \text { people }_{i, t-1}
$$

urban $_{i, t-1}$ means i region's city population in $\mathrm{t}-1$ year; people $_{i, t-1}$ means i region's population in $\mathrm{t}-1$ year.

\section{Results}

\subsection{The Measurement Results of TFP in Chinese Information Service Industry}

Based on obtained data, the total factor productivity and its decomposition value changes of Chinese information industry are calculated by using the nonparametric method of data envelopment analysis (DEA). Table 1 and Table 2 list total factor productivity change and decomposition respectively during the samples periods of Chinese information service industry.

\subsubsection{Annual total Factor Productivity Change Analysis of Chinese Information Industry}

According to Tab.1, there are four periods realizing the TFP growth from longitudinal analysis. They are 2008-2010, 2010-2012, 2012-2013 and 2013-2014. 2008-2010 and 20102012, particularly, have the largest annual growth increase with $6.3 \%$ and $4.7 \%$ respectively. Although total factor productivity change of the Chinese information service fluctuates during the period of 2008-2014, it is still moving forward at a speed of $1.1 \%$ with the main source of 
growth for the technical progress. The technical efficiency change may have certain negative influence on the growth of total factor. Positive role of technological progress is higher than the negativity of technical efficiency improvement, and the total production index appears a state of growth. In the later period, scale efficiency remains immobile while the technology change has a growth rate of $7.3 \%$. Besides, the pure technical efficiency index fluctuates gently around 1 , but overall average fall by $3.5 \%$; Scale efficiency index has retained at around 1 every year, and has increased by an average $0.3 \%$; Under the joint action of the pure technical efficiency and scale efficiency, technical efficiency change index fall by an average $5.8 \%$.

\begin{tabular}{c|c|c|c|c|c}
\hline Year & EC & TC & PC & SC & Mo \\
\hline $2008-2009$ & 0.962 & 1.054 & 0.982 & 0.98 & 1.013 \\
\hline $2009-2010$ & 0.988 & 1.077 & 1.038 & 0.951 & 1.063 \\
\hline $2010-2011$ & 0.779 & 1.297 & 0.856 & 0.91 & 1.011 \\
\hline $2011-2012$ & 0.982 & 1.003 & 0.975 & 1.007 & 0.985 \\
\hline $2012-2013$ & 1.023 & 1.024 & 0.938 & 1.091 & 1.047 \\
\hline $2013-2014$ & 0.939 & 1.012 & 1.011 & 0.929 & 0.951 \\
\hline Average & 0.942 & 1.073 & 0.965 & 0.976 & 1.011 \\
\hline
\end{tabular}

Table 1:Average Productivity Index and Its Decomposition of the Chinese Information Service Industry

\subsubsection{TFP Change Difference Analysis in the Development of Chinese Information Service Industry Region}

\begin{tabular}{|c|c|c|c|c|c|}
\hline Province & $\mathrm{EC}$ & $\mathrm{TC}$ & $\mathrm{PC}$ & $\mathrm{SC}$ & Mo \\
\hline China & 0.942 & 1.073 & 0.965 & 0.976 & 1.011 \\
\hline Tianjin & 0.967 & 1.094 & 0.951 & 1.016 & 1.058 \\
\hline Hebei & 1.018 & 1.062 & 1.000 & 1.018 & 1.080 \\
\hline Shanxi & 1.151 & 0.994 & 1.115 & 1.032 & 1.145 \\
\hline Liaoning & 0.914 & 1.078 & 0.919 & 0.995 & 0.985 \\
\hline Jilin & 0.999 & 1.026 & 1.006 & 0.993 & 1.026 \\
\hline Guangdong & 0.983 & 1.083 & 1.000 & 0.983 & 1.065 \\
\hline Shanghai & 1.001 & 1.013 & 0.986 & 1.015 & 1.013 \\
\hline Jiangsu & 0.978 & 1.091 & 0.992 & 0.986 & 1.067 \\
\hline Zhejiang & 0.907 & 1.078 & 0.901 & 1.007 & 0.978 \\
\hline Anhui & 0.901 & 1.083 & 0.929 & 0.969 & 0.975 \\
\hline Fujian & 0.924 & 1.098 & 0.931 & 0.993 & 1.014 \\
\hline Jiangxi & 0.945 & 1.101 & 0.966 & 0.979 & 1.041 \\
\hline Shandong & 0.899 & 1.032 & 0.901 & 0.998 & 0.928 \\
\hline Henan & 0.938 & 1.005 & 0.941 & 0.997 & 0.943 \\
\hline Inner Mongolia & 0.904 & 1.127 & 0.936 & 0.965 & 1.019 \\
\hline Beijing & 0.977 & 1.045 & 1.000 & 0.977 & 1.021 \\
\hline Hebei & 0.926 & 1.080 & 0.952 & 0.973 & 1.000 \\
\hline Hunan & 0.887 & 1.098 & 0.936 & 0.948 & 0.974 \\
\hline Hainan & 0.889 & 1.098 & 0.933 & 0.953 & 0.976 \\
\hline Guangxi & 0.887 & 1.071 & 0.895 & 0.991 & 0.950 \\
\hline Chongqing & 0.936 & 1.087 & 0.954 & 0.981 & 1.017 \\
\hline Sichuan & 0.978 & 1.059 & 0.986 & 0.992 & 1.036 \\
\hline Guizhou & 0.929 & 1.096 & 1.031 & 0.901 & 1.018 \\
\hline Yunnan & 0.911 & 1.098 & 0.958 & 0.951 & 1.000 \\
\hline Tibet & 0.910 & 1.098 & 1.017 & 0.895 & 0.999 \\
\hline Shaanxi & 0.889 & 1.073 & 0.894 & 0.995 & 0.954 \\
\hline Gansu & 0.911 & 1.112 & 0.951 & 0.958 & 1.013 \\
\hline Qinghai & 0.983 & 1.048 & 1.000 & 0.983 & 1.030 \\
\hline Ningxia & 0.911 & 1.079 & 0.995 & 0.916 & 0.983 \\
\hline Xinjiang & 0.911 & 1.098 & 0.968 & 0.942 & 1.000 \\
\hline Heilongjiang & 0.979 & 1.083 & 0.996 & 0.983 & 1.060 \\
\hline
\end{tabular}


Table 2:Average Productivity Index and Its Decomposition of Provincial Information Service Industry (2008-2014)

We found that there was a big variety of total factor productivity changes among the Chinese provincial information service according to Table 2 from horizontal comparison. Similar to the changes in front of the national, the variety of technological progress is still the kernel changes in total factor productivity differences between provinces information services. To research more in-depth on regional characteristic and difference of total factor productivity in information service, we will divide 31 provinces into three big economic regions: eastern, central and western according to their economic development characteristics by using Eviews 6.0.Table.3 shows the three major economic regions to total factor productivity changes in information services; we will have a detailed analysis.

\begin{tabular}{cccccc}
\hline Region & EC & TC & PC & SC & Mo \\
\hline China & 0.942 & 1.073 & 0.965 & 0.976 & 1.011 \\
Eastern & 0.945 & 1.072 & 0.951 & 0.993 & 1.012 \\
Central & 0.959 & 1.066 & 0.975 & 0.982 & 1.020 \\
Western & 0.926 & 1.085 & 0.978 & 0.948 & 1.004 \\
\hline
\end{tabular}

Table 3:Average Productivity Index and Its Decomposition of Regions Information Service Industry (2008-2014)

Table 3 shows the TFP changes in information services of China in three areas. In the whole, the TFP change of the central area is better than the national average and is the highest of 3 regions(Eastern:Beijing, Tianjin, Hebei, Liaoning, Shanghai, Jiangsu, Zhejiang, Fujian, Shandong, Guangdong, Guangxi, Hainan,Chongqing;Central:Inner Mongolia, Jilin, Amur River, Anhui, Jiangxi, Henan, Hebei, Hunan;Western:Sichuan, Guizhou, Yunnan, Tibet, Shaanxi, Gansu, Qinghai, Ningxia, Sinkiang ).However, the change index is small in eastern and western, and this may be due to the hard spread of technology by themselves. Meanwhile, the change trend of regions are coincident with national except eastern area, which fully shows that, central and western regions have achieved big promotions in technology innovation with the support of relevant national policies. And the technological progress is the main cause of information service industry TFP growth. Totally, the TFP change of Chinese information industry presents an upward trend, but its speed has fallen.

\subsection{Analysis of the Influence Factors about the Development of Chinese Information Service Industry Based on thePanel Data}

We can find significant differences among three regions by measuring Chinese provinces and regional information service productivity changes from 2008 to 2014. According to the above factors influencing TFP growth evaluation model, the results of the analysis are as follows:

\begin{tabular}{c|c|c|c|c|c}
\hline & Model(1) & Model(2) & Model(3) & Model(4) & Model(5) \\
\hline C & -14.251 & -14.265 & -13.634 & -9.84 & -14.769 \\
\hline $\operatorname{lnIDI}$ & 0.074 & 0.074 & 0.105 & 0.223 & 0.139 \\
\hline $\operatorname{lnRD}$ & & -0.001 & -0.001 & 0.009 & -0.028 \\
\hline $\ln$ DU & & & 0.013 & 0.049 & 0.033 \\
\hline $\ln$ GOV & & & & 0.103 & 0.053 \\
\hline $\ln U R B$ & & & & & -0.157 \\
\hline Adj R $^{2}$ & 0.9997 & 0.9997 & 0.9997 & 0.9998 & 0.9998 \\
\hline F & 706431 & 683524 & 662416 & 695938 & 714075 \\
\hline D.W. & 1.3753 & 1.375 & 1.3684 & 1.4929 & 1.5152 \\
\hline
\end{tabular}

Table 4:Regression Results of the Influence Factors about Regional Information Services in 
TFP

By Model (1), the coefficients in front of the variable information level are positive With the increase of all the factors, it is bigger and bigger, which shows that the improvement of informatization level has a positive promoting role in information service industry total factor productivity growth. Informatization has not only provided technical support for the development of information services, but also greatly improved production efficiency of each section.

By Model (2), the coefficient of variable R\&D is small and negative. This shows that technology advantage hasn't been fully reflected in recent years, therefore the ability to turng scientific research into technology innovation should be enhanced.

By Model (3), we conclude that the improvement of education level promotes TFP growth in information services, therefore, we should investin education to implement the knowledge diffusion, and strengthen regional elements flow to improve the level of informatization .

By Model (4), the coefficient is relatively small but positive before the government behavior and it shows that the current Chinese government scale and interventions for information service industry have little effect on total factor productivity. Theoretically, urbanization brings spatial agglomeration to population and economic activities, which can directly promote the trade efficiency and the evolution of the division of labor, thus improving and pulling the TFP growth.

By the Model (5), however, the coefficient before the urbanization level is negative. It may be because the current information service industry level is still low in China, and strong agglomeration and scale economies have not formed yet.

\section{Conclusion}

Based on the information panel data of China's 31 provinces from 2008 to 2014, this paper uses the productivity index (TFP) to analyze the dynamic change of information service industry, and illustrates the various factors affecting TFP, and then draws the conclusions: China information service TFP shows a growing trend, and technological progress is the largest driving power to achieve the overall growth. Meanwhile, the three areas (eastern, central and western) have different regional economic development in Chinese terms of information service, especially the central region of TFP. When it comes to the contributing factors, high level of informatization and education havea great positive effect on informatization development and the government behavior can effectively promote growth in information services TFP at present while the R\&D investment and urbanization level have certain negative influence ondevelopment.

\section{References}

[1]Abramovitz, Resource and output trends in the United Stated since 1870[J], American Economics Association(1956(05)),pp.5-23.

[2]C.W. Cobb, P.H. Douglas, A theory of production, 1928 (01) [M], Management Economics, Chinese Remin University Press, (in Chinese)

[3]R. Solow, A contribution to the theory of economic growth in 1956 [M],Advanced Macroeconomics, Y. Zhi-gang, Fudan University Press (2004). (in Chinese) 
[4]A. Charnes, W.W. Cooper, L. Seiford, Extremal principles and optimization dualities for khinchinkullback-leibler estimation, Optimization 9 (1978).

[5]R. Färe, S. Grosskopf, Measuring Productivity: A comment[J], International Journal of Operations \& Production Management 14 (1994).

[6]R. Fare, R. Grabowski, S. Grosskopf, Technical efficiency of philippine agriculture[J], Applied Economics 17 (1985).

[7]Ping Hua, The influence of different education level to the total factor productivity growth - from the empirical study of China's provinces[J], China Economic Quarterly (2005) 147-166.

[8]Xiguo Yin, Foreign direct investment, international trade and China's productivity growth research, based on nonparametric Malmquist index analysis of the experience[J], Journal of International Trade (2008) 89-97. (in Chinese)

[9]Qingwang Guo, Zhiyun Zhao, J. Jun-xue, Chinese province economic analysis of the total factor productivity [J], World Economy (2005) 46-53+80. (in Chinese) 